\title{
Chile ante el Sistema Interamericano: el caso Palamara
}

María José Eva Parada*

\section{Introducción}

La Corte Interamericana de Derechos Humanos (Corte IDH) tuvo la posibilidad de resolver en el año 2005 el caso Palamara Iribarne vs. Chile ${ }^{1}$. El derecho a la libertad de expresión, la libertad individual, la propiedad y el debido proceso en Chile, entre otros, fueron analizados por ese tribunal que, en noviembre pasado, emitió un fallo señalando que Chile había violado la Convención Americana sobre Derechos Humanos (CAHD) en algunas de sus disposiciones.

El presente comentario analizará el desarrollo que la Corte IDH realizó sobre el derecho a la libertad de expresión, la censura previa y las leyes de desacato, siendo esta la primera vez que se pronuncia sobre este tipo de normas nacionales, y sobre el derecho al debido proceso y protección judicial, que ha examinado en muchas ocasiones. Si bien el fallo aborda también otros derechos, los previamente indicados nos han parecido de especial interés porque las conclusiones a su respecto colocan a Chile en la necesidad de adecuar, en breve plazo, su ordenamiento interno para conformarlo con la CADH.

\section{Hechos del caso}

Los hechos que dan origen a este caso ocurren a comienzos del año 1993, cuando al señor Humberto Palamara Iribarne, oficial retirado de la Armada de Chile que en esos momentos se desempeñaba como empleado civil a contrata de la Armada de Chile, se le prohibió publicar su libro Ilamado "Ética y Servicios de Inteligencia" que abordaba aspectos relacionados con inteligencia militar y con la necesidad de adecuarla a ciertos parámetros éticos. El hecho de escribir este texto e intentar su publicación y haber realizado declaraciones en prensa al respecto, dieron origen al procesamiento del señor Palamara por los delitos de incumplimiento de deberes militares y desobediencia ${ }^{2}$ y por el delito de desacato ${ }^{3}$.

Por una parte, el delito de incumplimiento de deberes militares ${ }^{4}$ se habría configurado cuando el autor hizo publicar su libro sin esperar una autorización institucional, contraviniendo lo establecido en el artículo 89 de la Ordenanza de la Armada №487 de 1988, que exige permiso de la autoridad para realizar artículos de prensa. A su vez, el delito de desobediencia ${ }^{5}$ se fundó en la negativa del señor Palamara de detener la publicación del libro luego de que fuera informado de que la misma había sido prohibida ya que se estimaba que el contenido atentaba contra la seguridad y defensa nacional, y por prestar declaraciones a la prensa

* Abogada, Investigadora del Centro de Derechos Humanos de la Facultad de Derechote la Universidad de Chile.

1 Corte IDH, Caso Palamara Iribarne vs. Chile, sentencia de 22 de noviembre de 2005.

2 Causa $N^{\circ} 464$ ante el Juzgado Naval de Magallanes contra Humberto Palamara Iribarne por los delitos de desobediencia e incumplimiento de deberes militares (a este expediente se acumuló la causa $\mathrm{N}^{\circ}$ 465 por el delito de desobediencia). Ver hechos del caso en párrafos 63 a 63.71 de la sentencia comentada.

3 Causa N471/93 ante el Juzgado Naval de Magallanes por el delito de desacato. Ver párrafos 63.72 a 63.93 de la sentencia. En Chile el delito de desacato fue derogado de la Ley de Seguridad del Estado en el año 2001. A su vez, la Ley $\mathrm{N}^{\circ} 20.048$, de agosto de 2005, derogó los artículos 263 del Código Penal que establecía el delito de injuria contra autoridad y 265 que

Este comentario, junto con el documento principal a que se refiere, están disponibles en www.anuariocdh.uchile.cl 
establecía el delito de desacato o injuria grave contra la autoridad, y remplazó el artículo 264 que establecía el delito de desacato a la autoridad, entre otras modificaciones. Sin embargo, a la fecha, continúan vigentes normas del Código de Justicia Militar (CJM) que contemplan la figura del desacato.

4 Este delito se encuentra tipificado en el artículo $299 \mathrm{~N}^{\circ} 3$ del CJM: "Será castigado con presidio militar menor en cualquiera de sus grados o con la pérdida del estado militar, el militar: (...) $3^{\circ} \mathrm{El}$ que sin incurrir en desobediencia o en el delito previsto en el artículo 294, deje de cumplir sus deberes militares".

5 Este delito se encuentra tipificado en el artículo 336 del CJM: "El militar que fuera del caso antes contemplado, dejare de cumplir o modificare por iniciativa propia una orden del servicio impartida por su superior, será castigado: (...)" y 337 del CJM: "El militar que se negare abiertamente a cumplir una orden del servicio que le fuere impartida por un superior, será castigado: (...)".

6 Conforme al artículo 22 de Código penal chileno "son penas accesorias las de suspensión e inhabilitación para cargos y oficios públicos, derechos políticos y profesionales titulares en los casos en que, cuando se le había ordenado mantener reserva y no realizar comentarios públicos críticos respecto de las causas que se seguían en su contra.

Como consecuencia de la negativa de abstención de la publicación, se incautaron los libros existentes en la imprenta así como también todos los archivos que contenían información relativa a la publicación. Asimismo, se incautaron los ejemplares que se encontraban en el domicilio del señor Palamara y se le obligó a borrar del disco duro de su computador personal el texto íntegro del mismo. A su vez, se ordenó su prisión preventiva, la que se extendió por once días. Cabe hacer presente que, ni en la notificación de allanamiento de su vivienda ni en la de detención, se le indicó el delito por el cual estaba siendo procesado.

La sentencia respecto de estos delitos (incumplimiento de deberes militares y desobediencia) se dictó en junio de 1994 condenándosele a penas privativas de libertad que fueron sustituidas por el beneficio de reclusión nocturna ya que concurrían los requisitos legales necesarios, y a penas accesorias ${ }^{6}$. La sentencia de apelación redujo las penas impuestas y sustituyó el beneficio de reclusión nocturna por el de remisión condicional de la pena, dejando al procesado sometido a control administrativo durante el lapso de un año ${ }^{7}$. La Corte Suprema, en seguida, rechazó el recurso de casación ${ }^{8}$ interpuesto por el señor Palamara contra la sentencia de apelación.

En cuanto al delito de desacato, previsto en el artículo 264.3 del Código Penal ${ }^{9}$, en relación con los artículos 265 y 266 del mismo código, éste se habría configurado al momento en que el señor Palamara realizó declaraciones públicas ante la prensa criticando el actuar de la Fiscalía Naval en los procesos que se seguían en su contra, lo cual significó, a juicio de la fiscalía, una injuria grave en su contra. Consecuencia del procesamiento por este delito, Palamara también fue sometido a prisión preventiva. Pese a que la sentencia de primera instancia absolvió al acusado por considerar que el mérito de los antecedentes no había sido idóneo ni suficiente para establecer el ilícito, ni se había probado un ánimo para ofender a persona alguna, la Corte Marcial de la Armada, conociendo en segunda instancia, revocó la sentencia en enero de 1995 y lo condenó a 61 días de presidio menor y a penas accesorias Idem. La Corte Suprema, posteriormente, declaró sin lugar el recurso de queja presentado por la defensa.

Como consecuencia de los hechos previamente expuestos, en mayo de 1993 se puso término anticipado al contrato de trabajo del señor Palamara, lo cual le exigió mudarse de la ciudad donde vivía con su familia en busca de otras oportunidades laborales significando esto una separación familiar.

\section{Consideraciones de la Corte Interamericana de Derechos Humanos}

Como hemos anticipado, analizaremos dos derechos en particular: a) la libertad de expresión, por su vínculo con el delito de desacato al que fue condenada la víctima y por ser la primera vez en que la Corte IDH se 
pronuncia sobre este tipo de leyes, y b) las garantías procesales y protección judicial, por relacionarse con la sede en la cual fueron conocidos los delitos imputados al peticionario. Como hemos anticipado, pese a que esta sentencia aborda el análisis de la violación de otros derechos, nos parece particularmente interesante el desarrollo de estos dos.

\section{a) Libertad de Expresión}

El derecho a la libertad de expresión se encuentra consagrado en el artículo 13 de la CADH y ha sido conocido en diversas oportunidades por la Corte IDH.

Este último órgano, explicando el contenido del derecho a la libertad de expresión, ha señalado que comprende tanto el derecho a expresar las propias ideas y pensamientos, como el derecho y libertad de buscar, recibir y difundir informaciones e ideas de toda índole. De esta manera, al restringirse ilegalmente la libertad de expresión no sólo se viola el derecho de un individuo en particular, sino el de la sociedad toda de recibir ideas e informaciones. En este sentido, se ha reconocido una dimensión individual y una social de este derecho, donde la dimensión individual está dada por el derecho de cada uno a expresarse por cualquier medio y hacer llegar su expresión al mayor número de destinatarios posibles ${ }^{10}$; mientras que la social implica el derecho de todos a conocer opiniones, relatos y noticias. Al respecto, la Corte ha dicho que tiene tanta importancia el conocimiento de la opinión ajena como el derecho a difundir la propia ${ }^{11}$.

Además, siguiendo los estándares de otras instancias internacionales, la Corte IDH ha recalcado la importancia de la libertad de expresión para la democracia, señalando que debe ser considerada como la piedra angular de una sociedad democrática ${ }^{12}$. Asimismo, ha declarado que "[s] in una efectiva libertad de expresión, materializada en todos sus términos, la democracia se desvanece, el pluralismo y la tolerancia empiezan a quebrantarse, los mecanismos de control y denuncia ciudadana se comienzan a tornar inoperantes y, en definitiva, se crea el campo fértil para que sistemas autoritarios se arraiguen en la sociedad"13.

En el presente caso la Corte IDH reconoció que tanto el libro "Ética y Servicios de Inteligencia" como las declaraciones realizadas por el señor Palamara implicaban el ejercicio de la libertad de expresión desde la perspectiva personal y social, mediante el acceso a los lectores de la información contenida en el libro ${ }^{14}$. Agregó que, para garantizar efectivamente el derecho a la expresión, "no bastaba con que permitiera que escribiera sus ideas y opiniones, sino que tal protección comprendía el deber de no restringir su difusión, de forma tal que pudiera distribuir el libro utilizando cualquier medio apropiado para hacer llegar tales ideas y opiniones al mayor número de destinatarios, y que éstos pudieran recibir tal información"15.

En este sentido, la Corte IDH consideró violado el artículo 13 de la CADH ya que los actos tendientes a limitar el derecho a difundir las ideas mediante la prohibición de publicar el libro, la orden de incautación de no imponiéndolas especialmente la ley, ordena que las otras penas las Ileven consigo".

7 En la sentencia de apelación, de 2 de enero de 1997, se revocó la sentencia de primera instancia en relación al delito de desobediencia fundado en las entrevistas dadas por Palamara, ya que ese hecho había sido previamente analizado en un proceso paralelo que se siguió por delito de desacato.

8 La casación es un recurso extraordinario, pues procede si norma expresa lo autoriza, que tiene por objeto que se declare la nulidad de una resolución judicial ya sea por no cumplir requisitos de forma o ser contraria a derecho.

9 Este artículo establecía: "Cometen desacato contra la autoridad: (...) 3.- Los que injurian o amenazan:

Primero: A un senador o diputado por las opiniones manifestadas en el Congreso. Segundo: A un miembro de un tribunal de justicia por los fallos que hubiere dado. Tercero: A los ministros de Estado u otra autoridad en el ejercicio de sus cargos. Cuarto: A un superior suyo con ocasión de sus funciones.

En todos estos casos la provocación a duelo, aunque sea privada o embozada, se reputará amenaza grave para los efectos del presente artículo.

${ }^{10}$ Corte IDH, Caso Ricardo Canese, 
sentencia de 31 de agosto de 2004, párr.77; Caso Herrera Ulloa, sentencia de 2 de julio de 2004, párr. 109; Caso Ultima Tentación de Cristo, sentencia de 5 de febrero de 2001, párr. 65.

11 Ver Corte IDH Caso Ricardo Canese párr. 79; Caso Herrera Ulloa, párr. 111; Caso La Última Tentación de Cristo, párr. 66.

$12 \mathrm{Al}$ respecto ver de la Corte Europea de Derechos Humanos, por ejemplo, Handyside v. United Kingdom, sentencia de 7 de diciembre de 1976, párr. 49; Caso Lingens v. Austria, sentencia de 8 de julio de 1986, párr. 41. En la Corte IDH, Opinión Consultiva OC 5-85 sobre la Colegiación Obligatoria de periodistas.

${ }^{13}$ Corte IDH Caso Ricardo Canese, párr. 86; Caso Herrera Ulloa, párr. 116.

14 Corte IDH, Caso Palamara, párr. 69.

15 Idem, párr. 73.

16 Idem., párr. 77.

17 Corte IDH, Caso Ricardo Canesse, párr. 104.

18 Ver $\mathrm{CIDH}$, Informe sobre la compatibilidad entre las leyes de desacato y la Convención Americana sobre Derechos Humanos, de 1994. los ejemplares en la imprenta y domicilio del señor Palamara, la supresión de las versiones electrónicas del texto, las diligencias encaminadas a recuperar los libros en manos de terceras personas y la prohibición de realizar comentario sobre los procesos en su contra, constituían un acto de censura previa no compatible con la CADH. Así, pese a que había ejemplares impresos y panfletos de promoción, éstos no se distribuyeron y la gente no pudo acceder al contenido del mismo. Además, la Corte señaló que era lógico que la formación profesional y experiencia del señor Palamara lo ayudaran a escribir un libro como el del caso, sin que eso significara per se un abuso a su derecho a la libertad de expresión, señalando que, como se había comprobado, además, contenía información que era obtenible de fuentes abiertas. En este sentido señaló que:

"puede ocurrir que los empleados o funcionarios de una institución tengan el deber de guardar confidencialidad sobre cierta información a la que tienen acceso en ejercicio de sus funciones, cuando el contenido de dicha información se encuentre cubierto por el referido deber. El deber de confidencialidad no abarca a la información relativa a la institución o a las funciones que ésta realiza cuando se hubiere hecho pública. Sin embargo, en ciertos casos, el incumplimiento del deber de confidencialidad puede generar responsabilidades administrativas, civiles o disciplinarias" ${ }^{\prime 16}$.

En este sentido, la Corte IDH no analizó si había o no un deber de confidencialidad puesto que se había probado que en la elaboración del libro se había utilizado información proveniente de fuentes abiertas.

En cuanto a posibles restricciones a la libertad de expresión, tanto la Corte como otros organismos internacionales han reconocido que la libertad de expresión no es un derecho absoluto y que es posible establecer responsabilidades ulteriores por el ejercicio abusivo del derecho. A este respecto, la Corte reiteró lo señalado en fallos previos en el sentido de que el Derecho Penal es el medio más severo y restrictivo para establecer responsabilidades respecto de una conducta ilícita ${ }^{17}$, y entró a analizar las responsabilidades ulteriores a las que se vio sometido el señor Palamara, mediante la aplicación de normas de desacato.

Si bien las leyes de desacato no habían sido hasta la fecha abordadas por la Corte IDH, sí lo ha hecho la Comisión Interamericana de Derechos Humanos (CIDH), que ha señalado que contravienen un pilar fundamental de la democracia que contempla el escrutinio público ${ }^{18}$. En este caso la Corte aplicó criterios previamente desarrollados por la jurisprudencia en cuanto a que "(e)l control democrático, por parte de la sociedad a través de la opinión pública, fomenta la transparencia de las actividades estatales y promueve la responsabilidad de los funcionarios sobre su gestión pública, razón por la cual se debe tener una mayor tolerancia y apertura a la crítica frente a afirmaciones y apreciaciones vertidas por las personas en ejercicio de dicho control democrático. Ello se aplica a los funcionarios y miembros de la Armada, incluyendo aquellos que 
integran los tribunales"19. En este sentido, era esperable que se exigiera un mayor umbral de tolerancia a la Fiscalía Naval, no por la calidad del sujeto en particular, sino por las actuaciones que Ilevaba a cabo, que eran de interés público.

La Corte también reiteró la idea de que entre las restricciones que puedan aplicarse a un derecho, debe elegirse aquella que lo limite en menor escala y además deben estar orientadas a satisfacer un interés público imperativo, lo cual exige que la restricción sea proporcional al interés que la justifica y ajustarse al logro de ese objetivo afectando en la menor medida posible el ejercicio de la libertad de expresión. En este sentido, la Corte IDH estimó que la aplicación del delito de desacato fue una medida desproporcionada e injustificada que restringió la libertad de expresión del señor Palamara, pues las expresiones proferidas guardaban directa relación con las actuaciones de las autoridades de la justicia militar dentro de sus funciones, suprimiendo el necesario debate en un sistema democrático ${ }^{20}$.

Concluyó, entonces, que es necesario llevar a cabo una adecuación del derecho interno, ya que además de violarse el artículo 13 por restringirse la libertad de expresión, se había vulnerado el artículo 2 de la CADH "por haber incluido en el derecho interno normas sobre desacato contrarias al artículo 13 de la Convención, algunas aún vigentes". En relación al artículo 2 la Corte IDH, se mostró preocupada al constatar que pese a que Chile había realizado una modificación legal que derogó las normas de desacato en la ley penal ordinaria, se mantenía vigente en ese ordenamiento la figura de "amenaza" a las mismas autoridades que previamente eran el sujeto pasivo del desacato, caracterizada por ser una figura ambigua y poco limitada en cuanto a su aplicación. Exigió, por tanto, una aclaración al Estado de Chile en cuanto al alcance de esta norma en caso de que decidiera mantenerla. Asimismo, criticó la mantención de alguna normativa sobre el desacato en la legislación militar chilena.

En suma, en este fallo la Corte IDH reiteró lo previamente señalado por la CIDH en cuanto a la incompatibilidad de las leyes de desacato con la $\mathrm{CADH}$, por ser éstas una forma de restringir la libertad de expresión y de esa manera menoscabar el debate abierto en una sociedad democrática donde debe ser posible controlar a las instituciones estatales sin temor a una represión posterior, como ocurrió en el presente caso.

\section{b) Garantías Judiciales y Protección Judicial}

La CADH regula en los artículos 8 y 25 las garantías judiciales y la protección judicial respectivamente. Ambos artículos fueron abordados en este fallo por tratarse de hechos acaecidos en el marco de la justicia militar chilena en tiempos de paz.

En Chile la justicia militar quedó excluida de la reforma procesal penal que entró plenamente en vigencia a mediados del año 2005. Así, en este procedimiento sigue rigiendo un sistema inquisitivo con dos etapas
19 Corte IDH, Caso Palamara, párr. 83, Caso Ricardo Canese, párr. 97, Caso Herrera Ulloa, párr. 174.

${ }^{20}$ Caso Palamara, párr. 88. 
21 Ver Horvitz, María Inés, "Panorama sobre la competencia y la organización de los tribunales militares en tiempos de paz en algunos países latinoamericanos. La situación de la justicia militar en América Latina", en Hacia una reforma de la Justicia Militar, Mera, Jorge (ed.), Cuadernos de Análisis Jurídico 13 Universidad Diego Portales, 2002

22 Corte $\mathrm{CIDH}$, Caso Palamara, párr. 124. Se cita Corte IDH Caso Lori Berenson Mejía, sentencia de 25 de noviembre de 2004, párr. 142.

23 Corte IDH, Caso Palamara, párr. 132.

${ }^{24}$ Idem., 128 características, sumario y plenario, donde las garantías del debido proceso se ven francamente disminuidas. Es un proceso principalmente escrito en el que un fiscal realiza la investigación secreta que adjunta al expediente. La primera etapa, el sumario, es secreta y restringe la posibilidad de participación del imputado y la defensa, la cual solo puede intervenir al momento final de la investigación, donde se abre el plenario y se puede solicitar una etapa probatoria, la que, sin embargo, no invalida lo ya adjuntado durante el sumario. Al término del plenario, el juez militar dicta sentencia, no existiendo en ningún momento derecho a audiencia oral y pública.

Hoy en día cada vez más hay una tendencia a reducir el ámbito de aplicación de la justicia militar a tiempos de guerra, siendo los tribunales militares en tiempos de paz ampliamente criticados y progresivamente eliminados. Algunos ejemplos de países latinoamericanos donde la competencia militar está fuertemente restringida son El Salvador, Nicaragua, Uruguay, siendo este último uno de los más progresistas al aplicar justicia militar solamente al caso de delitos militares y al caso de estado de guerra quedando fuera del ámbito de competencia los delitos comunes cometidos por militares en tiempos de paz, cualquiera sea el lugar donde se cometan ${ }^{21}$. En este sentido, la Corte IDH ha señalado que bajo la justicia militar "sólo se debe juzgar a militares por la comisión de delitos o faltas que por su propia naturaleza atenten contra bienes jurídicos propios del orden militar ${ }^{\prime 22}$ ya que la justicia penal militar debe tener un alcance restrictivo y excepcional, vinculado con las funciones que la ley asigna a las fuerzas militares.

En el presente fallo la Corte IDH abordó la vulneración del derecho a ser oído por un juez competente, independiente e imparcial (artículo 8.1 CADH). En cuanto a la competencia del tribunal, la Corte, asumiendo que para el respeto al juez natural no basta que esté establecido en la ley, sino que además su competencia debe estar claramente indicada en ella, criticó la poca claridad de la competencia en términos de definir actos militares y actores de delitos de ese carácter. Al respecto señaló que "en las normas que definen la jurisdicción penal militar en Chile no se limita el conocimiento de los tribunales militares a los delitos que por la naturaleza de los bienes jurídicos penales castrenses protegidos son estrictamente militares y constituyen conductas graves cometidas por militares que atentan contra dichos bienes jurídicos. El Tribunal destaca que esos delitos sólo pueden ser cometidos por los miembros de las instituciones castrenses en ocasión de las particulares funciones de defensa y seguridad exterior de un Estado"23. Así, la Corte criticó la amplitud de la justicia militar que acarreó una sanción penal para quién debió haber sido sometido a un régimen laboral ${ }^{24}$. Estableció la Corte que las conductas por las que se sancionó a señor Palamara no pusieron en peligro los bienes jurídicos susceptibles de protección penal y que esos procesos no constituyeron el medio menos lesivo, como debe ser una restricción a un derecho, para que el Estado protegiera los intereses de la Armada. 
La configuración de los delitos imputados al señor Palamara exigía como sujeto activo un militar ${ }^{25}$, respecto de lo cual la Corte señaló que "el señor Palamara Iribarne, al ser militar en retiro, no revestía la calidad de "militar" necesaria para ser sujeto activo de dichos delitos imputados, y por ello no se le podían aplicar las referidas normas penales militares"26. Agregó, al respecto, que en Chile la determinación de una persona como militar es una tarea compleja porque exige la interpretación de diversas normas, abriéndose la posibilidad de una amplia interpretación. Estas amplias facultades de juzgamiento son, por tanto, contrarias al artículo 8.1 de la $\mathrm{CADH}$, insistiendo la Corte en que el juzgamiento de civiles debe corresponder a la justicia ordinaria.

Reconociendo la posibilidad de existencia de la justicia militar en tiempos de paz, la Corte indicó que "en caso de que el Estado considere necesaria la existencia de una jurisdicción penal militar, ésta debe limitarse solamente al conocimiento de delitos de función cometidos por militares en servicio activo. Por lo tanto, (...) debe establecer, a través de su legislación, límites a la competencia material y personal de los tribunales militares, de forma tal que en ninguna circunstancia un civil se vea sometido a la jurisdicción de los tribunales militares" 27 .

Por otra parte, en cuanto a la composición, la Corte analizó la estructura orgánica y composición de la justicia militar en Chile y concluyó que "(ésta) supone que, en general, sus integrantes sean militares en servicio activo, estén subordinados jerárquicamente a los superiores a través de la cadena de mando, su nombramiento no depende de su competencia profesional e idoneidad para ejercer las funciones judiciales, no cuenten con garantías suficientes de inamovilidad y no posean una formación jurídica exigible para desempeñar el cargo de juez o fiscales. Todo ello conlleva a que dichos tribunales carezcan de independencia e imparcialidad" 28 , cuestión que vulneraba el artículo 8.1 de la CADH.

Además del análisis de estos tres aspectos relacionados con la amplitud de la competencia de los juzgados militares y la falta de imparcialidad e independencia de sus tribunales, la Corte abordó el respeto a las garantías procesales de publicidad y defensa del imputado, contempladas en el artículo 8 de la CADH.

A este respecto la Corte señaló que la regla general de que el sumario sea secreto es de por sí contraria al derecho de defensa del imputado porque imposibilita el acceso al expediente lo cual impide una adecuada defensa. Asimismo, la imposibilidad del defensor de estar presente en las declaraciones del procesado y sólo poder solicitar diligencias sin conocimiento de la investigación que se llevaba a cabo, violó el derecho a ser asistido por un defensor. Así "la imposibilidad de acceder a las actuaciones realizadas durante la etapa del sumario y presentar pruebas impidieron que el señor Palamara Iribarne pudiera defenderse de forma adecuada"29. De esta manera concluye que "(p)or la propia estructura del proceso penal militar y la consiguiente falta de imparcialidad el Fiscal Naval no puede ser asimilado al juez que garantiza el derecho a ser oído"30, lo cual viola el artículo 8.1, 8.5 y 8.2.letras c), d), f) y g) de la CADH.
${ }^{25}$ Los artículos 6 y 7 del CJM definen quiénes son militares para efectos de la justicia militar.

26 Corte IDH, Caso Palamara, párr. 140.

27 Idem. párr. 256.

28 Idem. párr. 155.

29 Idem., párr. 177.

30 Idem., párr. 180. 
La Corte señaló, finalmente, que el hecho de haber sustraído al señor Palamara de la justicia ordinaria y de ser oído por un juez natural, "trajo como consecuencia que todos los recursos que éste interpusiera en contra de las decisiones militares que le fueron adversas y afectaban sus derechos fueran resueltos por tribunales militares que no revestían las garantías de imparcialidad e independencia y no constituían el juez natural", lo que violó el derecho a un recurso sencillo y rápido o a cualquier otro recurso efectivo ante jueces o tribunales competentes, consagrado en el artículo 25 de la CADH.

\section{Conclusiones}

De acuerdo a lo explicado previamente, el presente fallo es de gran trascendencia para Chile pues, entre otras cosas, le exige adecuar su ordenamiento interno no sólo en lo que dice relación con leyes de desacato sino también en lo que respecta a la justicia militar.

En mayo de este año (2006) se cumplen seis meses desde la dictación de la sentencia, y a la fecha solo es posible señalar como avance la constitución en enero pasado de una comisión que se encargaría de evaluar una reforma a la justicia militar, la cual aún no ha hecho público proyecto o propuesta alguna.

En nuestra opinión, si es que Chile decide, como corresponde, cumplir con la sentencia jurídicamente vinculante dictada por la Corte IDH, es necesario emprender a la brevedad medidas tendientes a adecuar nuestro ordenamiento a la regulación internacional, además de observar, indudablemente, las otras medidas de reparación indicadas por ese tribunal, entre las cuales están la publicación y restitución del libro censurado, lo que tampoco ha sucedido hasta la fecha. 